\title{
OPTIMIZATION OF A SMALL SCALE CONCENTRATED SOLAR POWER PLANT USING RANKINE CYCLE
}

\author{
Ahlem Bouguila ${ }^{1, *}$, Rachid Said $^{1}$
}

\begin{abstract}
A system for the exploitation of the available energy of the sun is proposed in this paper. The system involves a collector, a heat reservoir, a vapor generator, a set of direction control valves and a turbine. These components can be combined to form four closed different cycles in order to generate electricity or store heat according to the outdoor environment. An optimization method is proposed to optimize the energy collected at the shaft of the turbine for a given input sun power. The method establishes a functional relationship between the optimal mass flow rate through the collector, the sun input power and the optimal collected power at the shaft of the turbine. A similar functional relationship is established between the optimal temperature of the working fluid and the sun input power. The collected optimal energy is computed as a function of the sun input power for different temperatures of the vapor generator. The effect of the heat transfer coefficient and coefficient of radiation of StefanBoltzmann and the temperature of the vapor generator on the output optimal energy are investigated.
\end{abstract}

\section{Keywords: Optimization, Renewable Energy, Solar Energy, Energy Storage}

\section{INTRODUCTION}

Given the demographic and economic boom in the world, the energy demand is increasing tremendously. And the excessive use of fossil fuels have caused dangerous environmental issues like climate changes and resource shortages. For these reasons, there is a strong interest in eco-friendly and renewable energy sources like geothermal, hydro-power, solar energy, and wind energy. In this regard, solar energy is a good solution to substitute fossil fuels. In fact, it is the most abundant energy source. Actually, the sun emits energy at a rate of $3.81023 \mathrm{~kW} \mathrm{~m}^{-2}$, of which approximately $1.81014 \mathrm{~kW} \mathrm{~m}^{-2}$ is intercepted by the earth. $0,1 \%$ of this energy when converted at an efficiency of $10 \%$ would produce four times the world's generating capacity [1]. Therefore several solar power systems have been set all over the world in order to benefit from this free energy. But most existing power plants are developed in a large scale and are centralized. As a result, power loss occurs during distribution and waste heat from the power plants is not used. Thus, small scale power generation systems at specific locations such as public buildings, residential homes, hotels or rural areas are very interesting to develop. And fortunately, solar energy can easily be combined with a small scale power cycle in different ways.

In this paper we will focus on Concentrated Solar Power technologies (CSP). It is an effective way to use solar energy as a heat source in a power generation cycle. In fact, the CSP system uses mirrors or lenses to concentrate a large area of sunlight, into a small area and then produces electricity by converting the concentrated light into heat. It exists in different common forms, namely solar power tower, dish Stirlings, concentrating linear Fresnel reflector and parabolic trough. Of these, parabolic troughs is the most used technology in solar power systems to harvest sun energy for its simplicity. In the beginning of 2011, it has been installed around 29 plants in operation and around $1220 \mathrm{MWe}$ of installed power in the world, corresponding to $96,3 \%$ of the total operational concentrating solar power plants [2]. Parabolic Trough Collector (PTC) can be useful in many applications, like electricity generation, steam production and hot water. Recently, much research have been conducted to improve the efficiency of the plant. These researches are addressed to enhance the total efficiency of the plant by developing new control methodologies, conducting technical-economic analyses, conceiving new materials and optimizing the input parameters of the system. Several power cycles can be integrated in a CSP plant, namely, Joule-Brayton cycle, Stirling cycle and organic Rankine cycle. In the case of small-scale plants, an organic Rankine cycle is well adapted to this type of systems. Actually, it is a simple cycle including few components and requires no high maintenance.

This paper was recommended for publication in revised form by Regional Editor Hamadiche Mahmoud

${ }^{1}$ National Engineering School of Monastir, University of Monastir, Tunisia

${ }^{\star}$ E-mail address: ahlemb.bouguila@gmail.com

Orcid id: 0000-0002-7159-6417

Manuscript Received 18 September 2018, Accepted 2 October 2018 
Despite the several advantages of solar energy, its intermittency limits its use. In fact, it is a cyclic time-dependent energy source. Therefore, thermal energy storage (TES) systems are required that to reduce the mismatch between energy supply and energy demand. In fact, the integration of TES offers the possibility to use the solar power all time.

\section{SOLAR FIELD}

The Parabolic Trough Collector (PTC) is the key element in the solar field. It uses a mirrors to reflect and focus sun radiation towards a receiver tube. The latter absorbs the incoming solar radiation and transforms it into thermal energy, and then transfers it to a fluid medium circulating in the receiver pipe. The parabolic trough can be integrated with solar thermal power plants in two ways. First, it can run directly a steam turbine by generating steam. This way is known as Direct Steam Generation DSG. Second, the parabolic trough can heat up a heat transfer fluid in the solar field, which in turn heats another fluid via a heat exchanger to generate steam. In both cases, the parabolic trough can be used to run all sorts of steam turbine power plants. Many optimization studies have been conducted in order to improve the PTC efficiency [3]. One of the most important solutions to improve the PTC efficiency is the tracking system that maintains the focus of the collector on the receiver tube all day long. Hassan Fatthabali [3] has designed a high accurate off-line sensorless dual-axes sun tracker. In his design, it has been shown experimentally that $24,59 \%$ more solar energy was captured during one year when using the solar tracker. Jaramillo [4] proposed another solution to improve the PTC efficiency. He inserted a twisted tape in the receiver tube in order to increase the heattransfer there. He pointed out the conditions under which this solution can ameliorate the performance of the PTC. Almanza et al. [5] proposed to replace the steel absorber tube by copper in order to eliminate the thermal stress in the wall of the pipe, due to the smaller circumferential temperature differences. Here, we focus on the optimization of the working fluid mass flux associated with the optimal temperature in order to obtain the maximum output power.

\section{STORAGE SYSTEM}

Thermal energy storage (TES) provides a handy solution to reduce the mismatch between energy supply and energy demand [6]. Moreover, it is a way to homogenize the temperature of the fluid before it is piped into the evaporator. The stored fluid can be also used at night or when there is no sun in order to make the system operational all time. Therefore, TES systems can be integrated into solar power plants to mitigate short fluctuations in solar insolation and to improve dispatchability of the system. Several thermal energy storage technologies have been investigated in many works. Thermal energy storage systems using two tank molten salt systems are common applied for parabolic trough power plants with thermal oil as a heat transfer fluid [6]. But this technology is very expensive because of the high cost of the molten salt and the use of corrosion resistant material. Agustin M. et al. [7] made a numerical comparison between sensible and latent heat storage for the POWERSOL project and found that sensible heat storage gives a better result. In fact, the configuration with latent heat storage yields lower values of the efficiency of the cycle. M. M. Sorour [8] made an experimental investigation about the performance of a small size sensible heat storage unit made of gypsum rocks. The investigation focuses on the effect of various parameters on the system performances. Single tank thermocline system seems to be the best adequate for this type of systems, given its low cost, ease of maintenance, direct coupling between the solar field and the power block [9].

\section{FLUID SELECTION}

The fluid selection is of key importance for the collected energy and the cycle efficiency. It is a trade off between thermodynamic specification, safety, economical and environmental aspects. The fluid medium circulating in the solar field and in the storage tank must have certain properties. It should have a low freezing temperature in order to avoid freeze protection measures. Bellos et al. [10] investigated three working fluids, namely pressurized water, thermal oil and thermal oil with nanoparticles, and found that the use of the nanofluids increases the collector efficiency by $4,25 \%$. This is due to the increasing of the convective heat transfer co-efficient between the working fluid and the absorber. Selvakumar et al. [11] investigated the heat transfer and fluid flow characteristics of several fluids like helium, duratherm, molten salt, vegetable oil, and therminol. They found that therminol is the most appropriate heat transfer fluid for short flow length applications. In the present study, therminol 62 is selected to be the working fluid in the solar field. Therminol 62 offers an outstanding performance to $325^{\circ} \mathrm{C}$, an excellent thermal stability and a low vapor pressure. For the power cycle, a good ORC fluid must have an isotropic saturation curve, 
low freezing point, high stability temperature, high heat of vaporization, high efficiency, low specific volume, good availability and a low cost [12] [13]. And in order to minimize the components size and pressure losses, the fluid viscosity and the volumetric flow should be as low as possible [14]. Here, we mention some organic working fluids used in some researches. Hung et al. [15] and Hung [16] demonstrated that for energy recovery systems extracting energy from low temperature waste heat, R123 and R113 are cost effective working fluids [17]. Mohamed Rady et al. used therminol 66 as a working fluid in the conception of a small multi generation concentrated solar plant for a medical center in Egypt. Tchanche et al. [18] made a comparison between 20 working fluids and found that R134a is the most suitable for small scale solar applications. Here, we will use the same working fluid in the solar field and in the power cycle. For a more extensive reviews see [24] and [25].

\section{EXPANDER MODEL}

In a small and distributed power generation system, the temperature difference at the expansion process is not very high and the expected output power is not very high either. Thus, it is important to achieve high efficiency for the expansion process. Yet there are only few works that wherein expanders are developed for small power generation systems with good efficiency. In fact, two main types of expanders can be distinguished: the displacement and the turbo type. For the Turbo type, Pei et al. [19] developed a radial turbo-expander with a gearbox and obtained an efficiency of $42 \%$. The working fluid was air. Kang [20] tested a $30 \mathrm{~kW}$ radial turbine with HFC-245-fa as working fluid. The maximum electrical overall isentropic efficiency was about $67 \%$. Among displacement machines, the scroll expander is a good solution for this system. This type of machinery is conventionally applied as a scroll compressor in air conditioners with small capacity, and recently it has been modified to work as a scroll expander. It has a reduced number of moving parts, wide output power range and broad availability [21]. Lemort et al. [22] found that the efficiency of the machinery in the expander mode is reduced by about $10 \%$ compared to the compressor one. Note that the expander efficiency is about $60 \%$. Saitoh et al. [23] have used a scroll expander in a Rankine cycle in which water vapor is the working fluid and solar energy is used as the heat source. They obtained a total efficiency of about $5 \%$ based on solar radiation, i.e. only $5 \%$ of the solar radiation is the harvest. In the present study, a vapor turbine with an isentropic efficiency of $50 \%$ is used.

\section{SYSTEM OUTLINE}

The proposed system in this paper consists of a collector (C), heat reservoir (HR), vapor generator (VG), turbine (T), a set of direction control valves (DCV) and pumps (P). A collector is constituted of a parabolic solar collector oriented by a solar tracker which focuses the radiation to be absorbed by the first working fluid, as has been explained in the previous section. The heated fluid is, then, sent to the heat reservoir (HR) to store its energy, or to a second working fluid which, in turn, transfers its energy to the electricity generator via a convenient turbine. The organic Rankine cycle (the turbine) is connected to the solar field through a vapor generator. Figure 1 shows a schematic diagram of the system. The proposed system includes four possible closed cycles. The first, hot working fluid in the scheme is heated in the heat collector, then directed by DCV1 to the vapor generator where it transfers heat via the the heat exchanger (HE) and then sent back to the heat collector via the DCV4. This forms the first closed cycle. In the second case, the hot fluid is pumped from the heat collector, and directed via DCV1 to the heat reservoir (HR), then it is directed by DCV2 to the vapor generator where it transfers its energy to the second working fluid, and then it is directed back to the heat collector via DCV4 which forms the second closed cycle. In the third cycle, the hot fluid is pumped from the heat collector (HC), and directed to the heat reservoir (HR) via DCV1 where the energy is stored in the form of heat, and the fluid directed back to the heat collector (HC) via the DCV2. The third cycle is used to store energy. In the fourth cycle, the energy stored in the heat reservoir (HR) is used to generate electricity, the fluid is pumped from the vapor generator and directed via DCV4 to the pump, and then to the heat reservoir (HR) via DCV1 and to the vapor generator via DCV2. In the fourth cycle, the energy stored in the reservoir is used to generate electricity. In all cycles but the third the second heated working fluid is sent to the turbine (T) to generate electricity. Note that if there is no need for electricity, the hot fluid can be directed via DCV2 to be used for other purposes such as house heating for instance. The optimization method is developed for the second cycle which is constituted of a collector, heat reservoir and vapor generator connected to a turbine and alternator (A) via a vapor generator. The proposed method of optimization can be applied to the first cycle as well. 


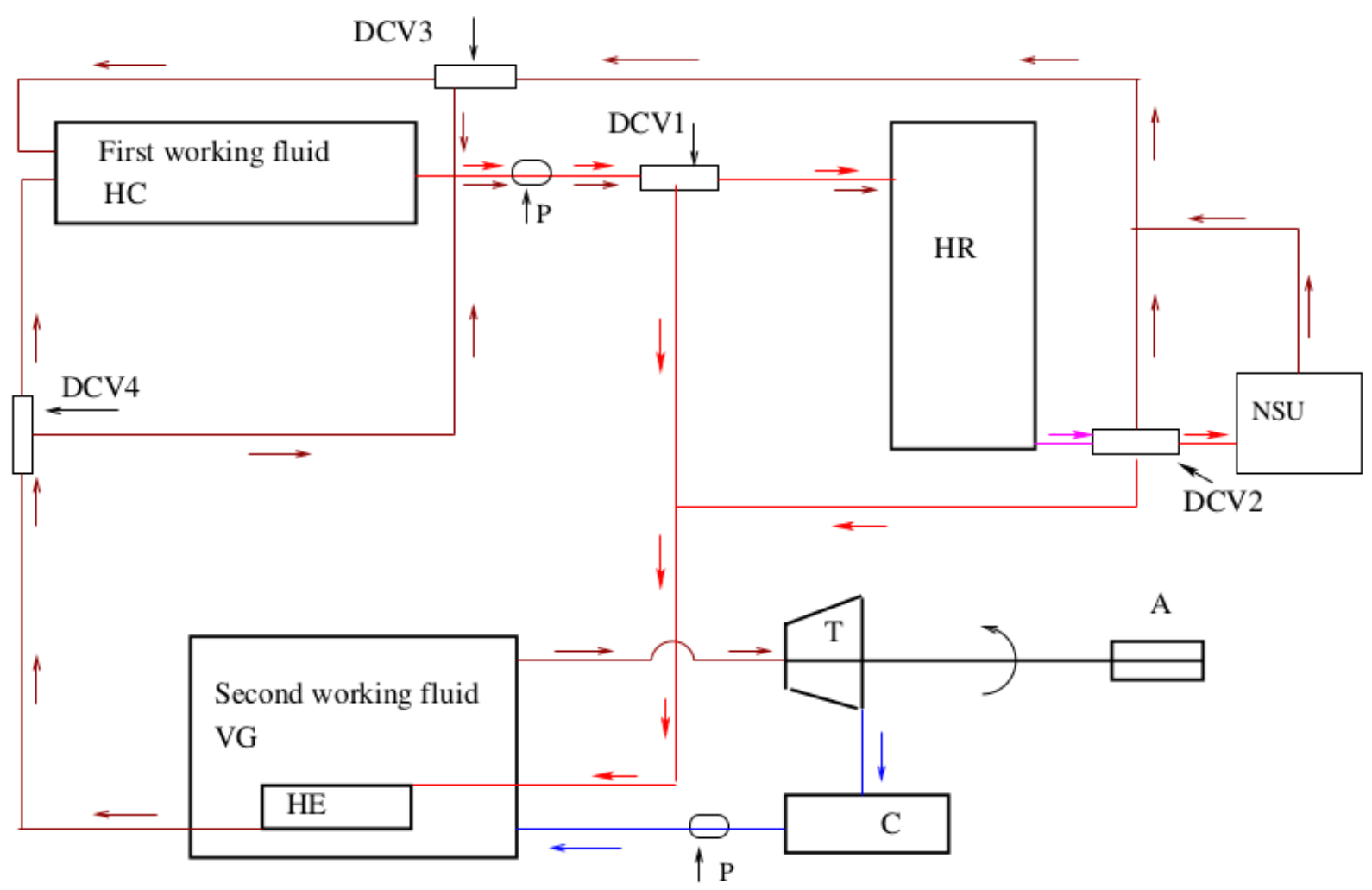

Figure 1. Schematic presentation of the installation. (HC) stands for the heat collector, (DVC) for the direction control valve, (HR) for the heat reservoir, (T) for turbine, (A) for the alternator, (VG) for the vapor generator, (HE) for the heat exchanger, (P) for the pump, (NSU) for the unspecified use and (C) for the condenser

\section{PROBLEM FORMULATION}

Let $\pi_{\mathrm{s}}$ be the solar energy per unit time received by the collector, part of this energy will be lost when it is sent through the canalization to a specific turbine to generate electricity. The evaluation of this unavoidable energy loss with precision requires knowledge of the flow, which can only be achieved by solving the flow equations in a complex geometry which is beyond the scope of this paper. In order to develop a tractable method and obtain useful results, an approximate estimate of the loss has to be done. Then, the obtained tractable method can be used to evaluate the amount of energy collected at the end of the cycle. The main hypothesis made here to evaluate the loss is that the temperature of the collector and the temperature of the heat reservoir are the same, or the difference between the two temperatures in comparison to each temperature is small enough to be neglected. This can be done by recirculating the working fluid by a secondary closed cycle connecting the reservoir and the collector or by a good insulation. Note that the temperature of the collector and the temperature of the heat reservoir are supposed to be homogeneous. The same hypothesis is made regarding the vapor generator i.e. the temperature of the vapor generator is supposed to be homogeneous. Let $\mathrm{T}$ be the mean temperature of the collector and the heat reservoir, the energy loss due to the combined conduction convection and radiation, noted $\mathrm{L}_{1}$, in the collector, in the canalization and in the heat reservoir is

$$
L_{1}=h S\left(T-T_{\text {ext }}\right)+\sigma\left(T^{4}-T_{\text {ext }}^{4}\right)
$$

where $\mathrm{T}_{\text {ext }}$ is the outdoor temperature, $\mathrm{h}$ is the total heat transfer coefficient and $\mathrm{S}$ is the heated surface in contact with the outdoor environment. The total heat transfer coefficient $\mathrm{h}$ includes the thermal resistance of the wall and heat transfer coefficient due to the free convection and forced convection, thus

$$
h=\left(\frac{1}{R e s}+\frac{1}{H}\right)^{-1}
$$


where Res is the resistance of the wall and $\mathrm{H}$ is the heat transfer coefficient due to the free convection and forced convection. Let

$$
T_{m}=\left(T-T_{e}\right) \alpha+T_{e}
$$

be the mean vapor generator temperature, where $\mathrm{T}_{\mathrm{e}}$ is the evaporation temperature of the second working fluid at atmospheric pressure, and $0<\alpha<1$, so the losses in the vapor generator are

$$
L_{2}=h_{e} S_{e}\left(T_{m}-T_{e x t}\right)+\sigma_{e} S_{e}\left(T_{m}^{4}-T_{e x t}^{4}\right)
$$

where $h_{e}$ is the total heat transfer coefficient of the vapor generator and $S_{e}$ is the surface of the vapor generator which is in contact with the outdoor environment. The remaining power is

$$
\begin{aligned}
\pi_{r}=\pi_{s}-L_{1} & -L_{2} \\
& =\pi_{s}-h S\left(T-T_{\text {ext }}\right)-\sigma S\left(T^{4}-T_{\text {ext }}^{4}\right)-h_{e} S_{e}\left(T_{m}-T_{\text {ext }}\right) \\
& -\sigma_{e} S_{e}\left(T_{m}^{4}-T_{\text {ext }}^{4}\right)
\end{aligned}
$$

This power is converted into steam in the vapor generator at $\mathrm{T}_{\mathrm{m}}$ temperature. The steam production rate is

$$
\pi_{r}=L \dot{m}_{v}
$$

where $\mathrm{L}$ is the latent heat and $\dot{m}_{v}$ is the mass rate of vapor. The power generated by the turbine per unit mass steam flux is

$$
e=\eta \int_{p_{m}}^{p_{0}} p d v
$$

where $\mathrm{p}_{\mathrm{m}}$ is the pressure steam in the vapor generator, $\mathrm{p}_{0}$ is the pressure steam at the outlet of the turbine, i.e. in the condenser, and $\eta$ is the energetic efficiency of the turbine. The gas in the turbine is supposed to be isentropic and the energy loss by friction is taken into account via the efficiency coefficient $\eta$. The gas is supposed to be perfect so that the ideal gas law can be used to evaluate the integral in the above equation. The equation of state gives

$$
\frac{v}{v_{0}}=\left(\frac{p}{p_{0}}\right)^{\left(\frac{-1}{\gamma}\right)} \text { and } \frac{v}{v_{0}}=\left(\frac{p}{p_{0}}\right)^{-1 / \gamma}
$$

where $\mathrm{v}_{0}$ is the specific volume of the vapor of the second working fluid at the outlet of the turbine. Using the above equations to evaluate the integral in equation 7 , the energy per unit mass can be written as a function of $T_{m}$ and $T_{0}$ :

$$
e=\eta \frac{v_{0} p_{0}}{\gamma-1}\left(\frac{T_{m}}{T_{0}}-1\right)=\frac{\eta R}{\gamma-1}\left(T_{m}-T_{0}\right)
$$

where $\mathrm{e}$ is the amount of energy per unit mass transferred from the second working fluid to the shaft of the turbine. The whole output turbine power is given by the relation, to say, $\pi_{t}=e \dot{m}_{v}$

Using equation 5 and equation 6 to eliminate $\dot{m}_{v}$, the output turbine power is written as a function of the temperature, input sun energy, the total heat transfer constant and Stefan-Boltzmann constant, that is

$$
\begin{aligned}
\pi_{t}=e \dot{m}_{v}= & \frac{\eta R}{L(\gamma-1)}\left[\pi_{s}-h S\left(T-T_{e x t}\right)-\sigma S\left(T^{4}-T_{e x t}^{4}\right)-h_{e} S_{e}\left(T_{m}-T_{e x t}\right)\right. \\
& \left.-\sigma_{e} S_{e}\left(T_{m}^{4}-T_{e x t}^{4}\right)\right]\left(T_{m}-T_{0}\right)
\end{aligned}
$$




\section{OPTIMAL TEMPERATURE}

The optimal temperature which maximizes the turbine output power solves the following equation

$$
\frac{\partial \pi_{t}}{\partial T}=0
$$

Thus, the optimal temperature $\mathrm{T}$ satisfies,

$$
\begin{aligned}
-h S-4 \sigma S T^{3} & -h_{e} S_{e} \alpha-4 \sigma_{e} S_{e} \alpha T_{m}^{3}\left(T_{m}-T_{0}\right) \\
& +\left[\pi_{s}-h S\left(T-T_{\text {ext }}\right)-\sigma S\left(T^{4}-T_{e x t}^{4}\right)-h_{e} S_{e}\left(T_{m}-T_{\text {ext }}\right)\right. \\
& \left.-\sigma_{e} S_{e}\left(T_{m}^{4}-T_{\text {ext }}^{4}\right)\right] \alpha=0
\end{aligned}
$$

The above equation is a fourth order polynomial of the optimal temperature that maximizes the turbine output power $\mathrm{T}$, which can be solved numerically. It is found that the above equation has two complex conjugate solutions and two real solutions of opposite singe, and that for all the used values of the involved constants. The two complex conjugate solutions and the real negative one are ignored. The real positive solution is used for the optimization.

\section{OPTIMAL FLOW MASS RATE}

In order to obtain the optimal flow mass rate of the first working fluid associated with the computed optimal temperature, the energy balance of the collector and the heat reservoir analysis is used to obtain

$$
\pi_{s}=+h S\left(T-T_{e x t}\right)+\sigma S\left(T^{4}-T_{e x t}^{4}\right)+C_{p} \dot{m}\left(T-T_{m}\right)
$$

where $\mathrm{C}_{\mathrm{p}}$ is the specific heat capacity of the first working fluid, $\dot{m}$ is the flow mass rate of the first working fluid, $\mathrm{T}_{\mathrm{m}}$ is the temperature of the first working fluid at the entrance of the collector, supposed to be equal to the temperature of the first working fluid in the vapor generator, and $\mathrm{T}$ is the mean temperature of the first working fluid in the collector and in the heat reservoir. $h$ is the total heat transfer coefficient of the collector and of the heat reservoir, $\sigma$ is a Stefan-Boltzmann radiation coefficient of the collector and of the heat reservoir, $\mathrm{S}$ is the total surface of the collector and of the heat reservoir in contact with the outdoor environment. The mass flow rate through the collector can be written as a function of the optimal temperature, that is

$$
\dot{m}=\left[\pi_{s}-h S\left(T-T_{\text {ext }}\right)-\sigma S\left(T^{4}-T_{\text {ext }}^{4}\right)\right]\left[C_{p}\left(T-T_{m}\right)\right]^{-1}
$$

\section{NON-OPTIMAL SOLUTION}

Let the sun input power $\pi_{\mathrm{s}}$ be known and an arbitrary mass flow rate of the first working fluid $\dot{m}$ be imposed on the collector, then equation 14 can be solved to obtain the mean temperature $\mathrm{T}$, and equation 10 can be used to obtain the power transferred to the turbine shaft. This solution can be obtained for some selected mass flow rates of the first working fluid and is referred herein to as a non-optimal solution.

\section{NUMERICAL RESULTS AND DISCUSSION}

In all the numerical simulations presented in this paper the following numerical values are used for the control parameters unless specified otherwise. Heat transfer coefficient is $\mathrm{h}=\mathrm{h}_{\mathrm{e}}=5 \mathrm{Wm}^{-2} \mathrm{~K}^{-1}$, Stefan-Boltzmann radiation coefficient is $\sigma=\sigma_{\mathrm{e}}=5.67 \times 10^{-8} \mathrm{Wm}^{-2} \mathrm{~K}^{-4}$, the exterior surface of the collector and of the heat reservoir is $\mathrm{S}=2 \mathrm{~m}^{2}$ and the exterior surface of the vapor generator is $\mathrm{S}_{\mathrm{e}}=1 \mathrm{~m}^{2}$, the latent heat of the second working fluid is $\mathrm{L}=$ $383 \mathrm{~kJ} \mathrm{~kg}^{-1}$, the specific heat of the second working fluid is $\mathrm{C}_{\mathrm{p}}=2150 \mathrm{JK}^{-1}$, the evaporation temperature of the second working fluid is $T_{e}=380 \mathrm{~K}$, the outdoor environment temperature is $T_{\text {ext }}=320 \mathrm{~K}$ and the turbine energy efficiency is $\eta=0,5$. 


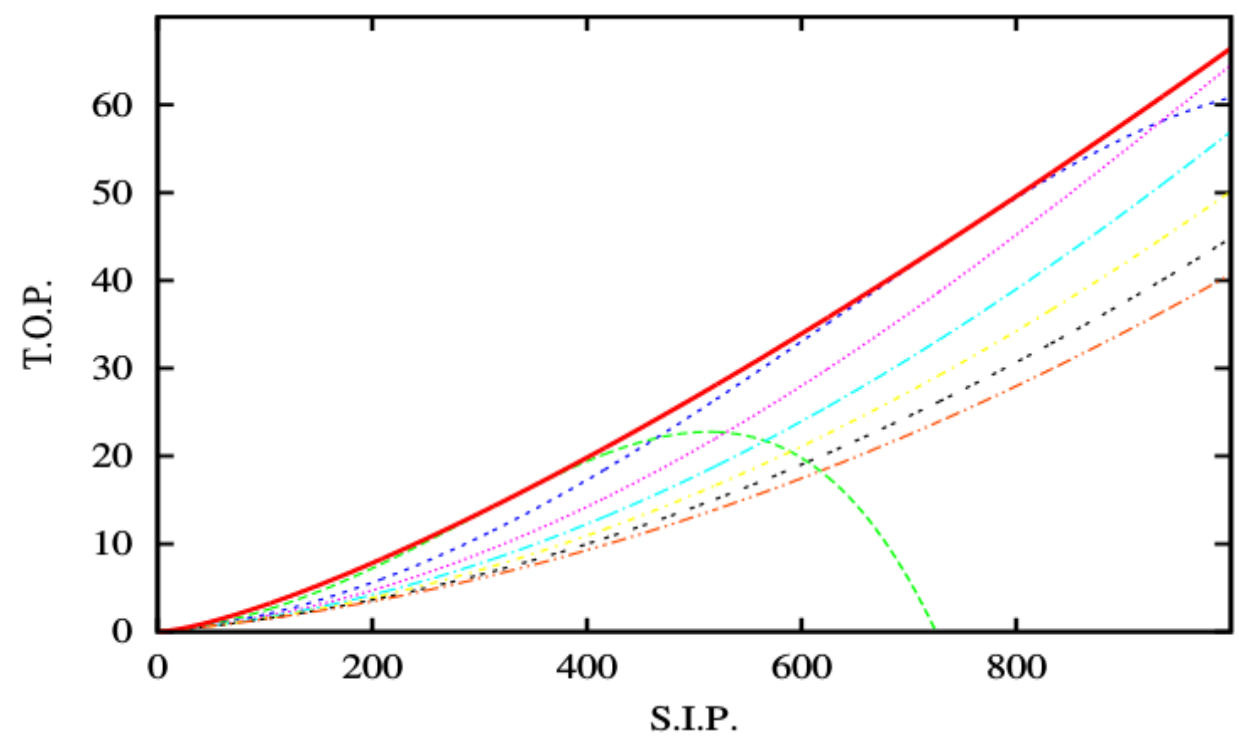

Figure 2. Turbine output power (T.O.P) in $\mathrm{kW}$ versus input power (S.I.P) IN Kw. The red thick and solid line represents the optimal turbine power, the other lines represent the turbine power obtained without optimization, and after a selected collector's input mass flow rate. Green line $\dot{m}=0.3 \mathrm{~kg} \mathrm{~s}^{-1}$, blue line $\quad \dot{m}=0.5 \mathrm{~kg} \mathrm{~s}^{-1}$, magenta line $\dot{m}=0.7 \mathrm{~kg} \mathrm{~s}^{-1}$,cyan line $\dot{m}=0.9 \mathrm{kgs}^{-1}$, yellow line $\dot{m}=1.1 \mathrm{~kg} \mathrm{~s}^{-1}$, black line $\dot{m}=1.3 \mathrm{~kg} \mathrm{~s}^{-1}$ and orange line $\dot{m}=1.5 \mathrm{~kg} \mathrm{~s}^{-1}$. $\alpha=0.1$

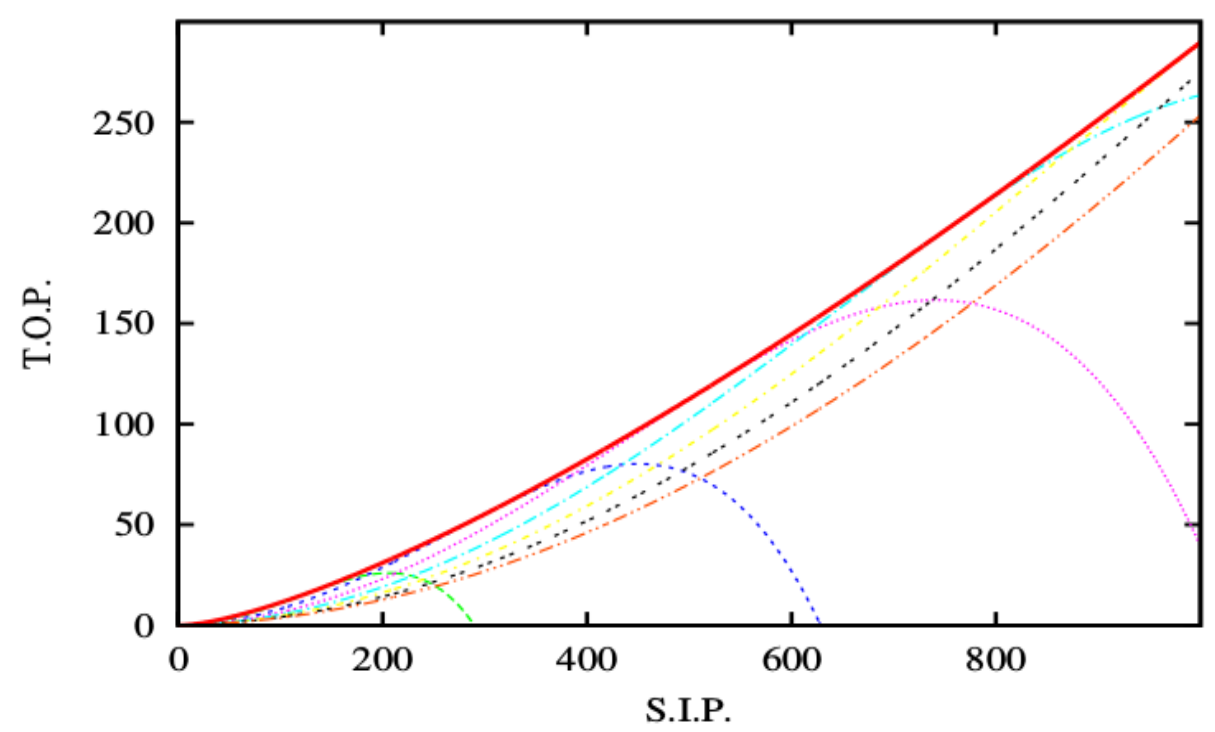

Figure 3. Turbine output power (T.O.P) in $\mathrm{kW}$ versus input power (S.I.P) IN Kw. Line legend as in figure $2 . \alpha=0.5$

The turbine optimal output power (T.O.P.) is plotted versus the sun input power (S.I.P.) in figure 2 for $\alpha=0.1$ and in figure 3 for $\alpha=0.5$. The obtained turbine non-optimal output powers are plotted in the same two figures versus the sun input power for some selected values of the mass flow rate. Figures 2 and 3 show that the obtained nonoptimal turbine power never exceeds the optimal value as one would expect. Note that in the two figures, the nonoptimal turbine output power increases with the increase of the mass flow rate until it becomes close to the optimal value, and then decreases with the further increase of the mass flow rate. In the case of small non-optimal mass flow rate and for a large input energy value, the turbine output power decreases with the increase of the input sun energy, this is because the energy losses by radiation become important as the fluid becomes very hot for small mass flow rates of the first working fluid. 


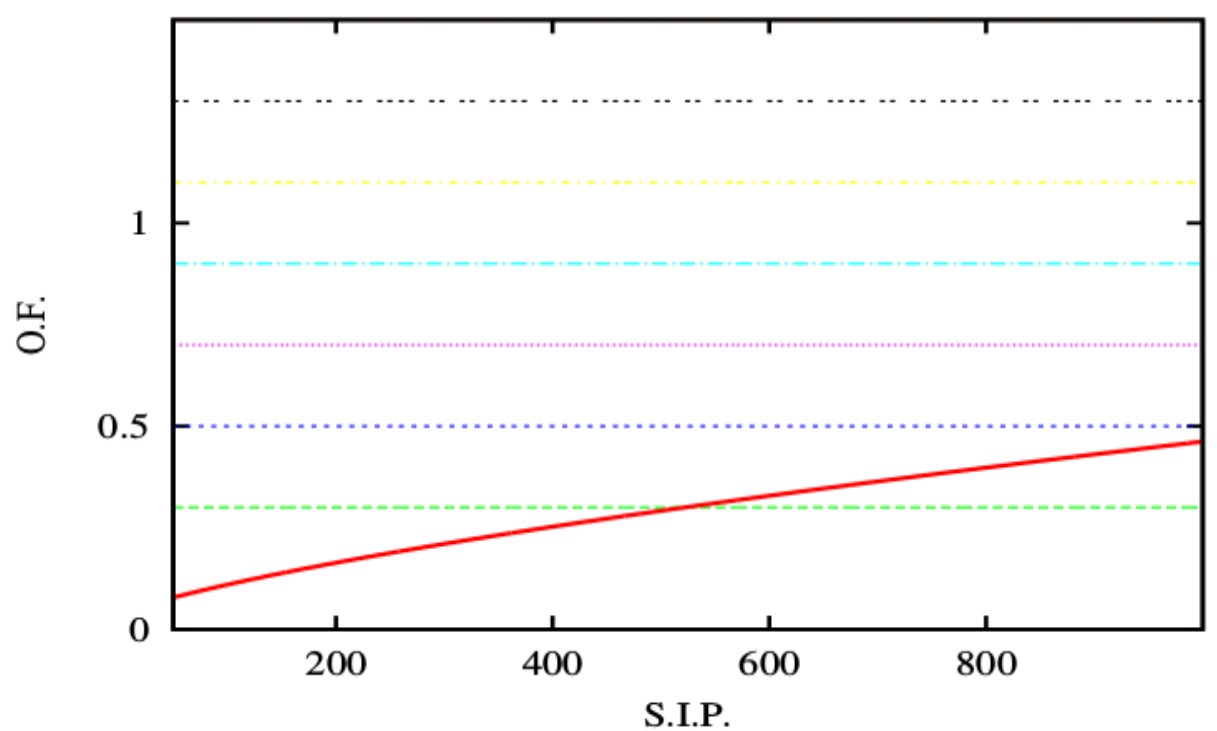

Figure 4: Optimal mass flow rate and selected mass flow rate (O.F) in $\mathrm{kg} \mathrm{s}^{-1}$ versus the sun input power in $\mathrm{kW}$. The thick solid red line represents the collector optimal mass flow rate, and the others represent the imposed collector mass flow rate. Line legend as figure 2

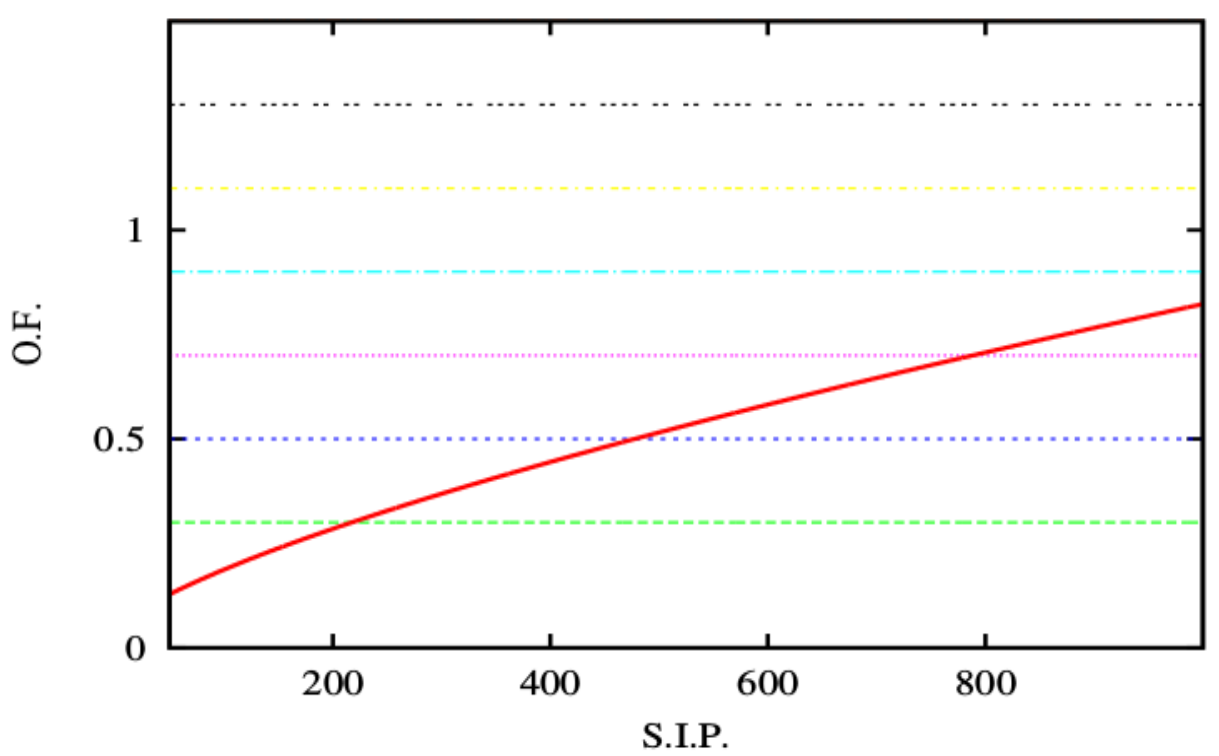

Figure 5: Optimal mass flow rate and selected mass flow rate (O.F) in $\mathrm{kg} \mathrm{s}^{-1}$ versus the sun input power in $\mathrm{kW}$. The thick solid red line represents the collector optimal mass flow rate, and the others represent the imposed collector mass flow rate. Line legend as figure 2. $\alpha=0.5$

Figure 4 and Figure 5 show the optimal mass flow rate through the collector versus the sun input power for $\alpha$ $=0.1$ and $\alpha=0.5$, respectively. The seven imposed mass flow rates used in figures 2-3 are plotted in the same figures for comparison. As expected, the optimal mass flow rate increases when the input power is increased. This result is useful when an efficient solar system is designed because it allows the selection of optimal mass flow rate for a given input energy. Note that the optimal mass flow rate does not match any of the seven non-optimal and imposed mass flow rates. 


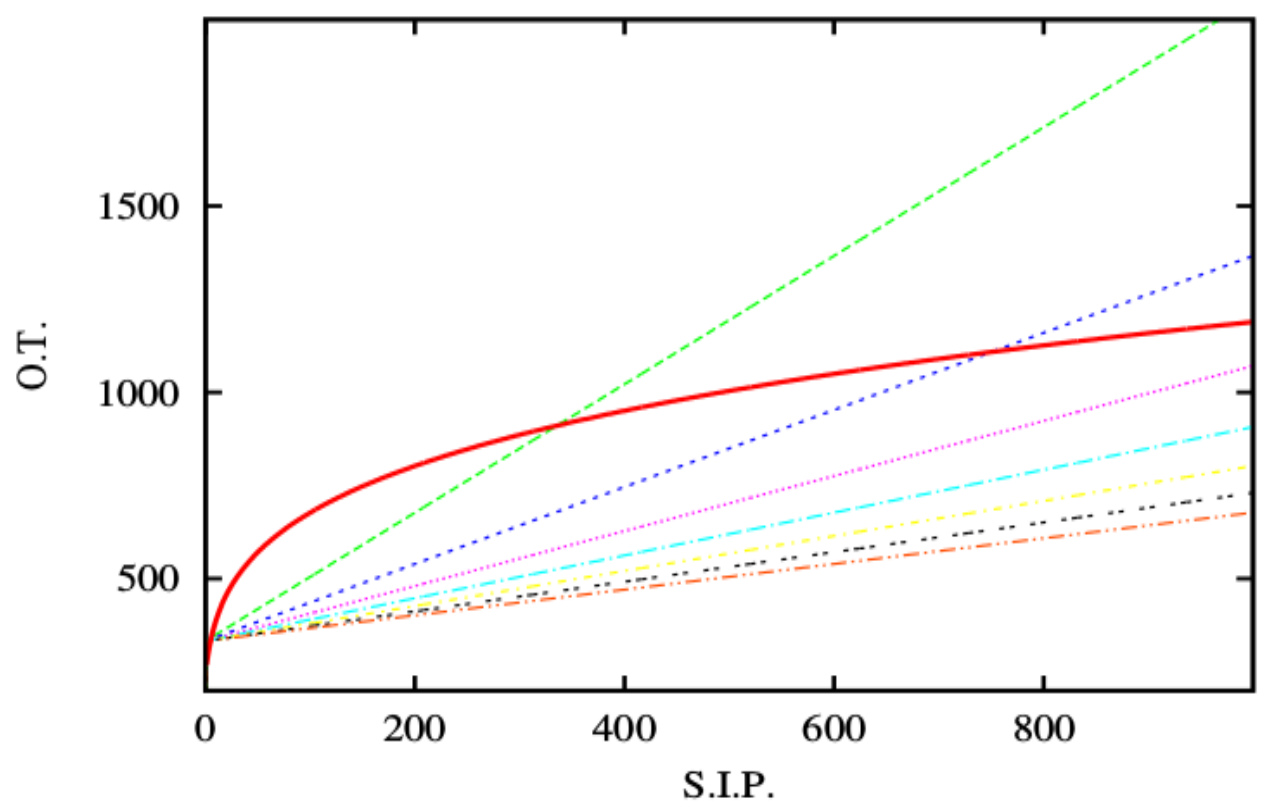

Figure 6: Optimal working fluid temperature $\mathrm{T}(\mathrm{O} . \mathrm{T})$ in $\mathrm{K}$ and the non-optimal working fluid temperature versus the sun input power (S.I.P) in Kw. The thick solid red line represents the optimal temperature $\mathrm{T}$ of the working fluid, and the others represent the temperature of the working fluid $\mathrm{T}$ when the mass flow rate is selected. Line legend as in figure 2

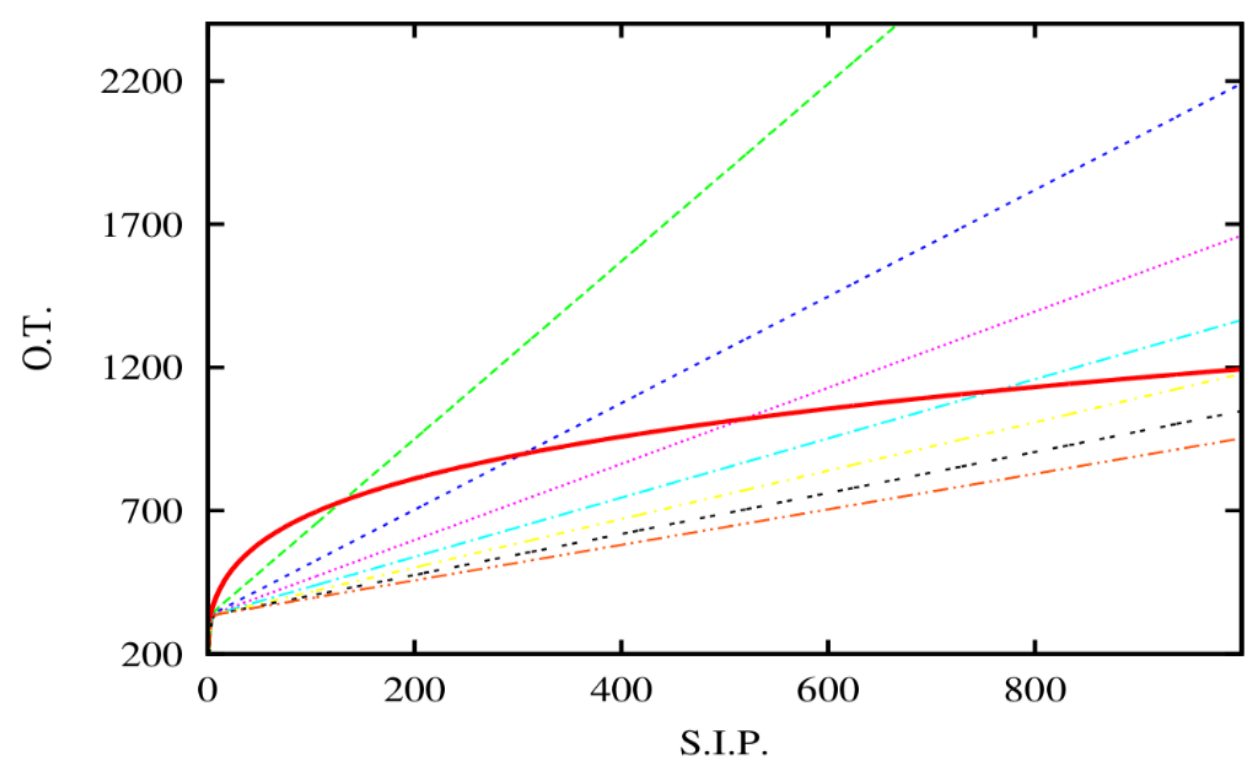

Figure 7: Optimal working fluid temperature $\mathrm{T}$ (O.T.) in $\mathrm{K}$ and the non-optimal working fluid temperature versus the sun input power (S.I.P.) in $\mathrm{kW}$. The thick solid red line represents the optimal temperature $\mathrm{T}$ of the working fluid, and the others represent the temperature of the working fluid $\mathrm{T}$ when the mass flow rate is selected. For the labels see figure 2 but $\alpha=0.5$

Figure 6 and 7 show the optimal mean temperature of the working fluid in the collector and in the heat reservoir versus the sun input energy for $\alpha=0.1$ and $\alpha=0.5$. The non-optimal working fluid mean temperature for the seven selected rates used in figures 2-3 are plotted in the same figure for comparison. As expected, The optimal temperature does not match any of the seven non-optimal ones. 


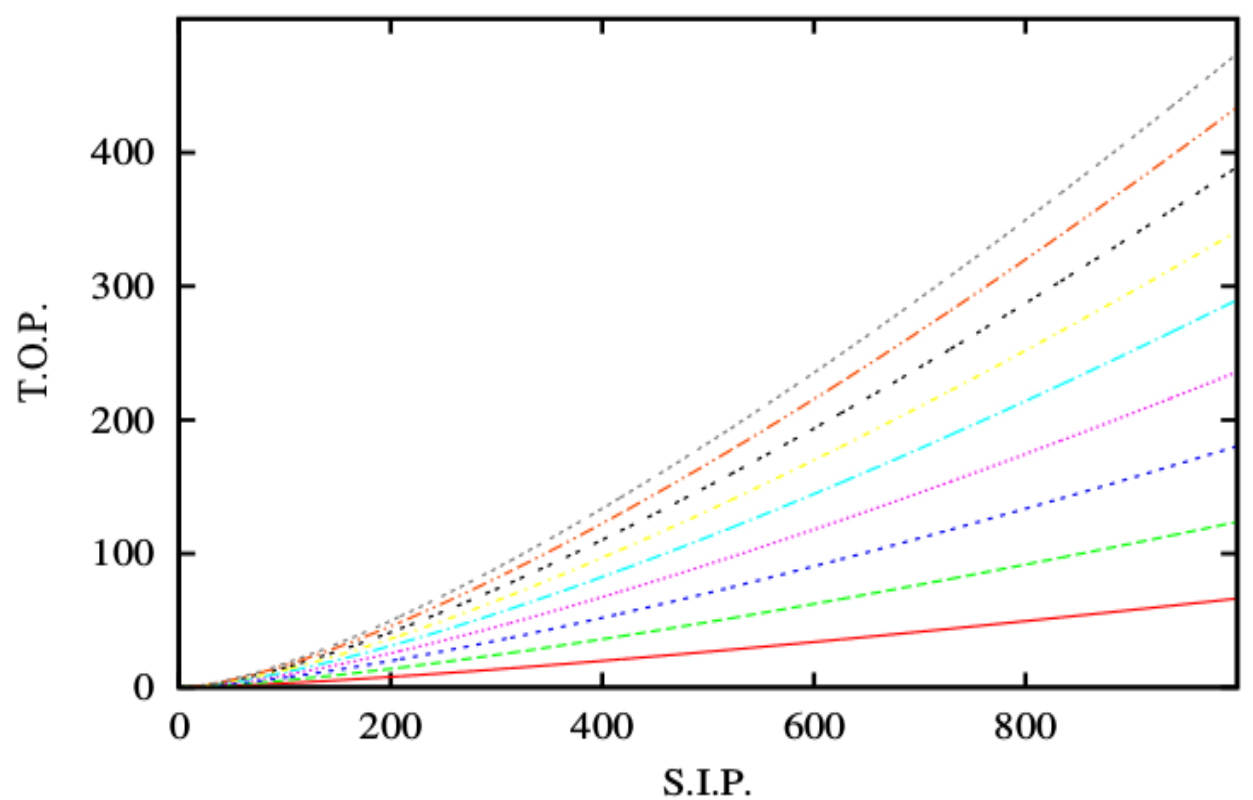

Figure 8: Optimal turbine output power (T.O.P.) in kW versus sun input power (S.I.P.) in kW, for some values of $\alpha$. From bottom to top, $\alpha=0.1, \alpha=0.2, \alpha=0.3, \alpha=0.4, \alpha=0.5, \alpha=0.6, \alpha=0.7, \alpha=0.8$ and $\alpha=0.9$

Figure 8 shows the optimal turbine energy output for some values of $\alpha$, it is found that the output energy is an increasing function of $\alpha$. Note that about half of the input energy is recovered at large $\alpha$, as the energetic efficiency of the turbine is supposed to be $50 \%$, half of the energy is lost in the turbine, and the remaining loss is due to radiation, free convection and forced convection. Note that $\alpha$ is close to unity only if the losses by convection and radiation are very small i.e. the system has a good insulation.

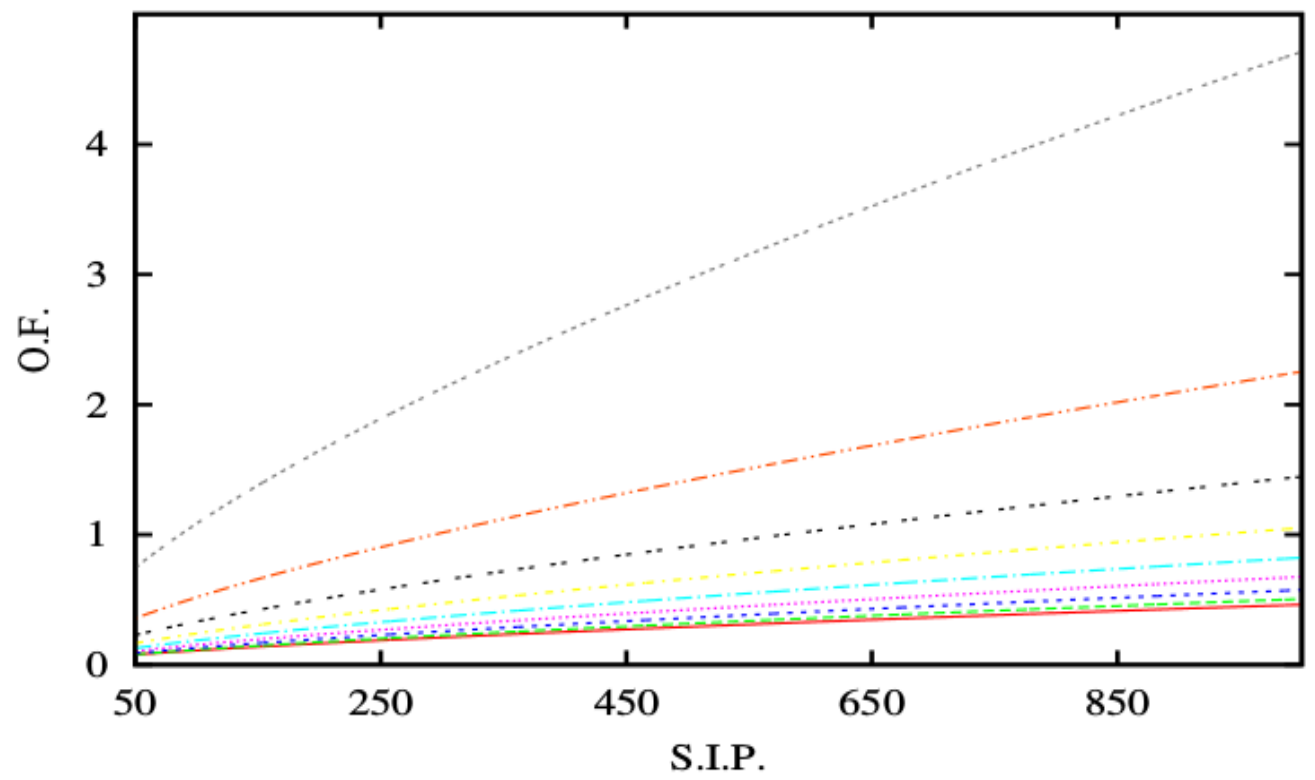

Figure 9: Optimal collector mass flow rate (O.F.) in $\mathrm{kg} \mathrm{s}^{-1}$ versus the sun input power (S.I.P.) in $\mathrm{kW}$ for some values of $\alpha$. Line legend as in figure 8

The optimal mass flow rate (O.F.) versus the sun input power (S.I.P.) is shown in figure 9 for some selected values of $\alpha$, the figure shows that the optimal mass flow rate does not vary strongly with $\alpha$ unless the value of $\alpha$ approaches the unity. Note that the optimal mass flow rate is an increasing function of $\alpha$. 


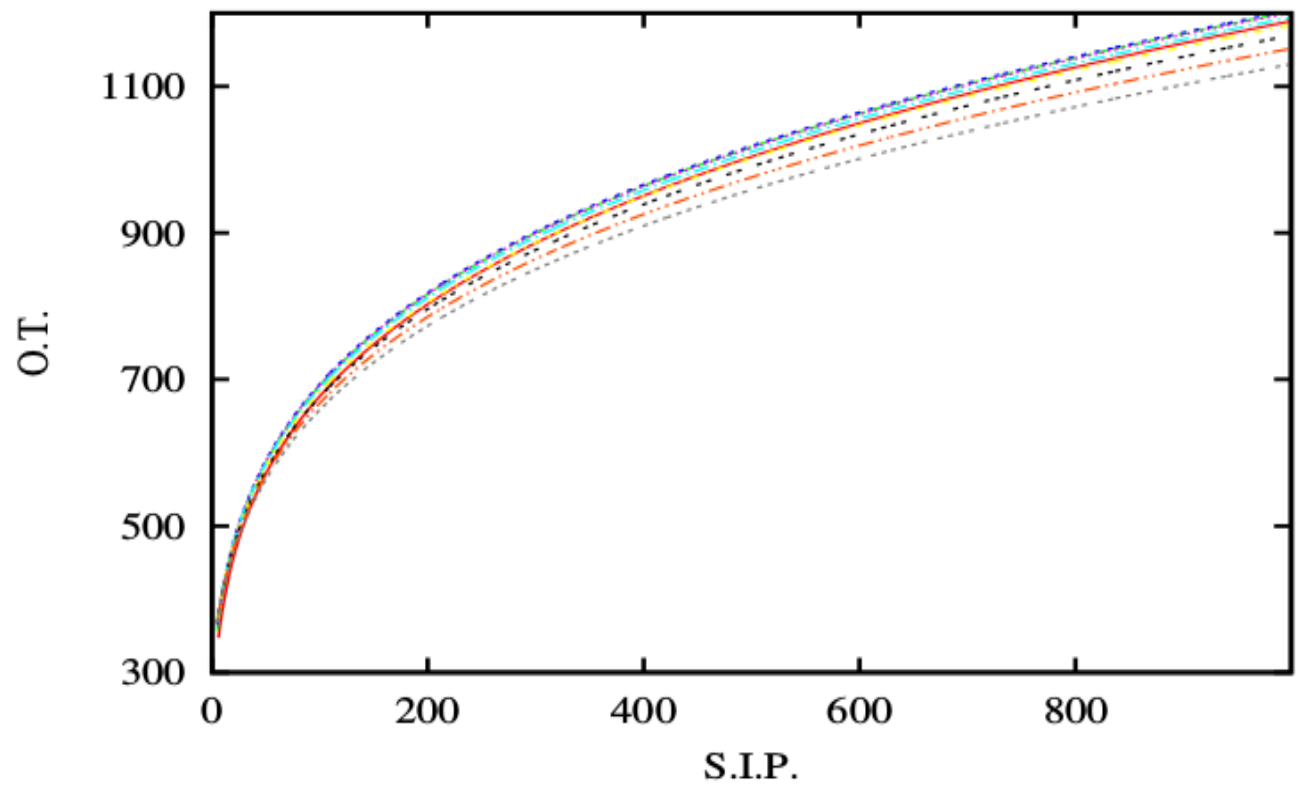

Figure 10: Optimal temperature (O.T.) in $\mathrm{K}$ versus the sun input power (S.I.P.) in $\mathrm{kW}$ for some values of $\alpha$. Line legend as in figure 8

The optimal temperature for some values of $\alpha$ is shown in figure 10, it is found that the optimal temperature does not vary strongly with $\alpha$, either. However, the figure shows that the mean temperature of the first working fluid is not a linear function of $\alpha$, for small $\alpha$ the mean temperature increases with the increase of $\alpha$, for large $\alpha$ the mean temperature decreases with the increase of $\alpha$.

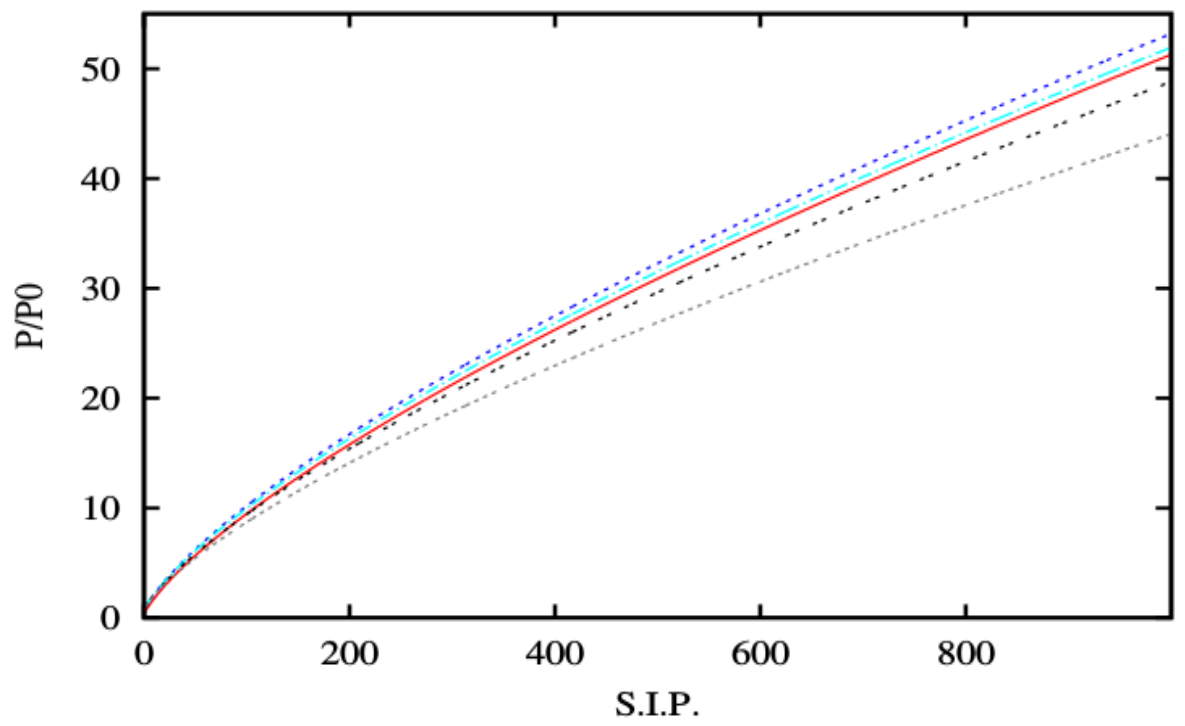

Figure 11: Optimal dimensionless pressure $\mathrm{P} / \mathrm{P}_{0}$ versus the sun input power (S.I.P.) in $\mathrm{kW}$ for some values of $\alpha . \mathrm{P}_{0}$ is the pressure in the condenser. Line legend as in figure 8

The dimensionless pressure inside vapor generator versus the sun input power for some values of $\alpha$ is shown in figure 11. The figure shows that pressure in the vapor generator is very high which should be taken into account during its design in order to support high stress. Figures 10-11 show that the optimal pressure and the optimal temperature are non linear and non monotonic function of $\alpha$, in that they increase when $\alpha$ is increased in the vicinity of its smallest value, namely 0 , but they decrease when $\alpha$ is increased in the vicinity of its largest value, namely 1 . 


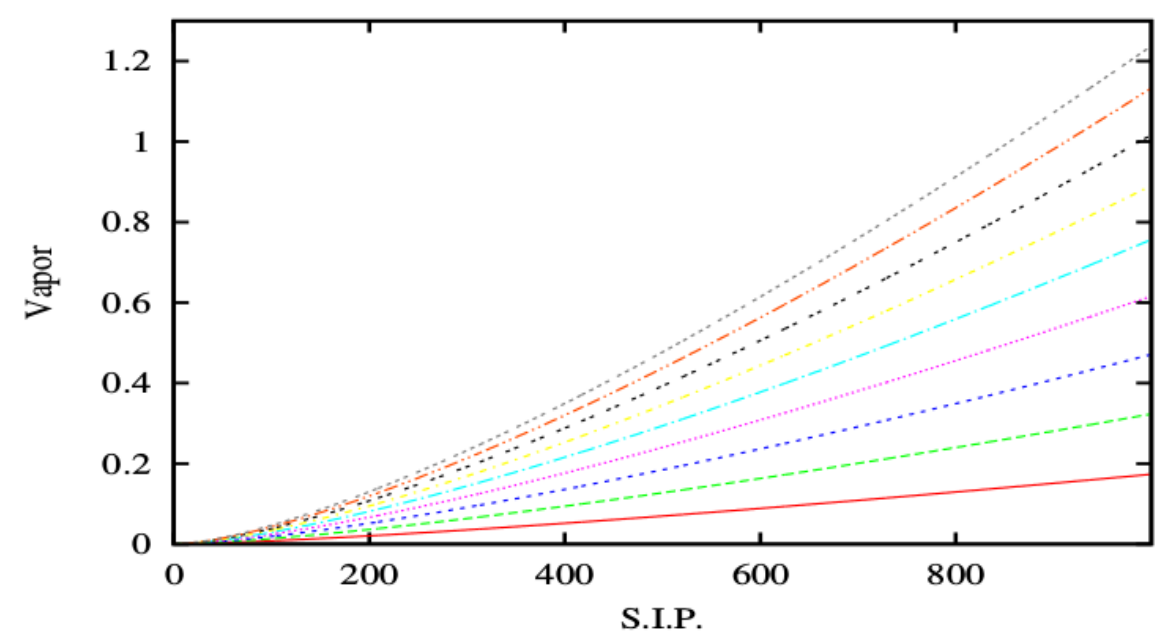

Figure 12: Optimal vapor mass rate en $\mathrm{kg} \mathrm{s}^{-1}$ produced by vapor generator versus the sun input power (S.I.P.) for the some values of $\alpha$. Line legend as in figure 8

Figure 12 shows the mass of the produced vapor. The amount of the produced vapor is an increasing function of $\alpha$. It is of interest to note that the optimization method provides a system that generates a small vapor quantity but at highest temperatures and high pressures ratios as expected.

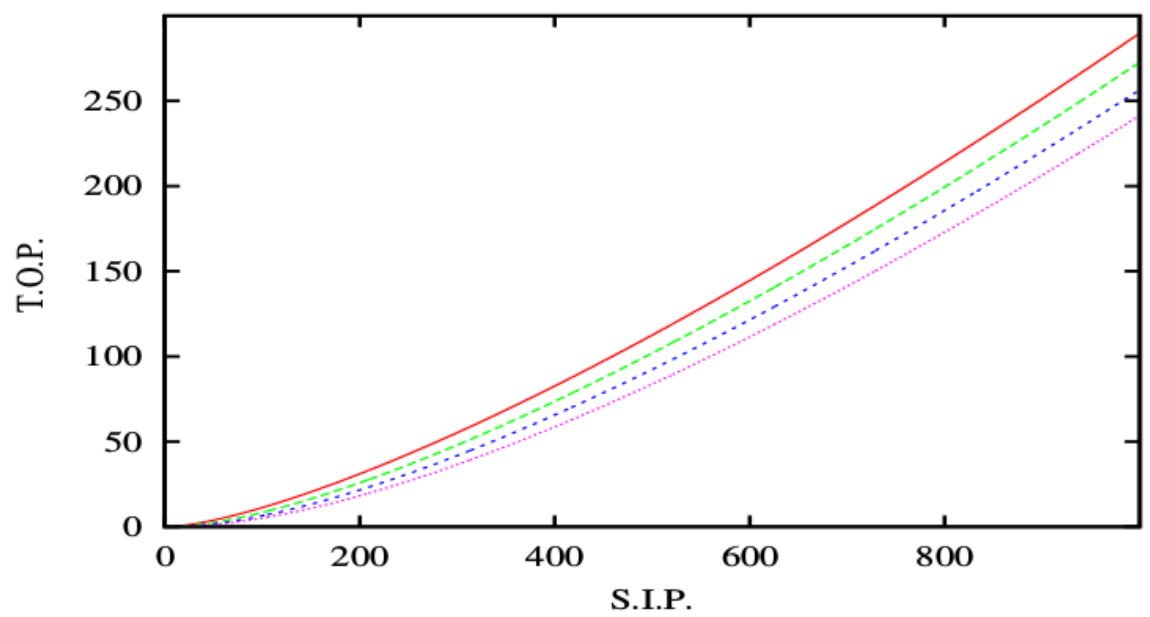

Figure 13: Optimal turbine output power (T.O.P.) in $\mathrm{kW}$ versus sun input power (S.I.P.) in $\mathrm{kW}$, for some values of heat transfer coefficient $h, h$ is increased, starting from the reference state, with an increment $\Delta h=20$. From top to bottom, $\mathrm{h}=\mathrm{h}_{\text {ref }}, \mathrm{h}=\mathrm{h}_{\text {ref }}+\Delta \mathrm{h}, \mathrm{h}=\mathrm{h}_{\text {ref }}+2 \Delta \mathrm{h}, \mathrm{h}=\mathrm{h}_{\text {ref }}+3 \Delta \mathrm{h}, \mathrm{h}_{\text {ref }}=5$

Figure 13 shows the effect of the heat transfer coefficient on the optimal output energy. As expected, the output optimal energy decreases with the increase of $h$.

\section{CONCLUSION}

In this paper, we investigated the variation of the turbine output power in terms of solar input power for different mass flow rates. To this end, a system constituted of a collector, heat reservoir, turbine, vapor generator and direction control valves is proposed. Using the direction control valves, four closed cycles can be formed to generate electricity or store heat. A mathematical method is developed to optimize the collected energy at the shaft of the turbine. The method leads to a functional relationship between the sun input power and the mass flow rate through the collector. A similar relationship between the working fluid temperature and mass flow rate is found. The method is used to predict the optimal output power collected at the turbine shaft for different temperature of the vapor generator. It has been found that the collected energy is an increasing function of the temperature of the vapor generator. The effects of heat transfer coefficient and Stefan-Boltzmann radiation coefficient on the optimal collectedpower are evaluated. 


\section{REFERENCES}

[1] M. Thirugnanasambandam, S. Iniyan, R. Goic, A review of solar thermal technologies.Renewable and Sustainable Energy Reviews. Volume 14, issue, 1, January 2010, pages 312-322.

[2] I.L. Garca, J. L. Alvarez, D. Blanco, Performance Model for Parabolic Trough Solar Thermal Power Plants with Thermal Storage: Comparison to Operating Plant Data, Solar Energy. Volume 85, Issue 10, October 2011, Pages 2443-2460.

[3] H. Fathabadi, Novel high efficient offline sensorless dual-axis solar tracker for using in pho-tovoltaic systems and solar concentrators, Renewable Energy. Volume 95, September 2016, pp.485-494.

[4] O.A. Jaramillo, M. Borunda, K.M. Velazquez-Lucho, M. Robles,Parabolic trough solar collector for low enthalpy processes: An analysis of the efficiency enhancement by using twisted tape inserts. Renewable Energy. Volume 93, August 2016, Pages 125-141.

[5] R. Almanza, A.Lentz, G.Jimenez, Receiver behavior in direct steam generation with parabolic troughs. Solar Energy. Volume 61, Issue 4, October 1997, Pages 275-278.

[6] K. Bhagat, S.K. Saha, Numerical analysis of latent heat thermal energy storage using encapsulated phase change material for solar thermal power plant. Renewable Energy. Volume 95, September 2016, Pages 323-336.

[7] A.M. Delgado-Torres, L. Garca-Rodrguez, Design recommendations for solar organic Rankine cycle (ORC)powered reverse osmosis (RO) desalination. Renewable and Sustainable Energy Reviews. Volume 16, Issue 1, January 2012, Pages 44-53.

[8] M.M. Sorour, Performance of a small sensible heat energy storage unit. Energy Conversion and Management. Volume 28, Issue 3, 1988, Pages 211-217.

[9] M. Rady, A. Amin, M. Ahmed, Conceptual Design of Small Scale Multi-Generation Concentrated Solar Plant for a Medical Center in Egypt. Energy Procedia. Volume 83, December 2015, Pages 289-298.

[10] E. Bellos, C. Tzivanidis, K.A. Antonopoulos, G. Gkinis, Thermal enhancement of solar parabolic trough collectors by using nanofluids and converging-diverging absorber tube. Re-newable Energy. Volume 94, August 2016, Pages 213-222.

[11] P. Selvakumar, S.A. Prasanth, N. Rakesh, A.Vignesh, Fluid flow and heat transfer analysis on multiple parabolic trough collectors by varying heat transfer fluids, Undergraduate Project Thesis, India: Anna University of Technology Coimbatore, 2011.

[12] S. Quoilin, Experimental Study and Modeling of a Low Temperature Rankine Cycle for

Small Scale Cogeneration PhD Thesis, Belgia: Aerospace and Mechanical Engineering Department Thermodynamics Laborator, 2007.

[13] B.F. Tchanche, G. Papadakis, G. Lambrinos, A. Frangoudakis, Fluid selection for a low-temperature solar organic Rankine cycle. Applied Thermal Engineering. Volume 29, Issues 1112, August 2009, Pages 2468 2476.

[14] J. Nouman, Comparative Studies and Analyses of Working Fluids for Organic Rankine Cycles ORC, Master of Science Thesis, KTH School of Industrial Engineering and Management; 2012, SE-100 44 Stockolm.

[15] T.C. Hung, T.Y. Shai, S.K. Wang, A review of organic rankine cycles (ORCs) for the recovery of lowgrade waste heat. Energy. Volume 22, Issue 7, July 1997, Pages 661-667.

[16] T.C. Hung, Waste heat recovery of organic Rankine cycle using dry fluids. Energy Conversion and Management. Volume 42, Issue 5, March 2001, Pages 539-553.

[17] T. Saitoh, N.Yamada, S. Wakashima, Solar Rankine Cycle System Using Scroll Expander,Journal of environment and engineering. Volume 2, No 4,2007, pages 986-992.

[18] B.F. Tchanche, G. Papadakis, G. Lambrinos, A. Frangoudakis, Fluid selection for a low-temperature solar organic Rankine cycle. Applied Thermal Engineering. Volume 29, Issues 1112, August 2009, Pages 2462476.

[19] G.Pei, Y. Li, J. Li, Performance evaluation of a micro turbo-expander for application in low-

temperature solar electricity generation. Journal of Zhejiang University-SCIENCE A. Volume 12, Issue 3, March 2011, pages 207-213.

[20] S.H. Kang, Design and experimental study of ORC (organic Rankine cycle) and radial turbine using R245fa working fluid. Energy. Volume 41, Issue 1, May 2012, Pages 514-524. 
[21] R. Zanelli, D. Favrat, Experimental investigation of a hermetic scroll expander-generator.Proceedings of the International Compressor Engineering Conference at Purdue. 1994, pages 459-464.

[22] V.Lemort, S. Quoilin, C. Cuevas, J.Lebrun, Testing and modeling a scroll expander integrated into an Organic Rankine Cycle. Applied Thermal Engineering. Volume 29, Issues 1415, October 2009, Pages 3094-3102.

[23] T.S. Saitoh, H. Okudaira, A.Hoshi, Study on Solar Rankine Cycle Engine of Displacement-type. Transactions of the Japan Society of Mechanical Engineers. Volume 69, Series B, No 680,2003, pages $142-148$.

[24] L. Navarro, A. de Gracia, D. Niall, A. Castell, M. Browne, S. J. McCormack, Ph. Grffiths, L. F. Cabeza, Thermal energy storage in building integrated thermal systems: A review. Part 2. Integration as passive system. Renewable Energy. Volume 85, January 2016, Pages 1334-1356.

[25] S.A. Kalogirou, S. Karellas, V. Badescu, K. Braimakis, Exergy analysis on solar thermal systems: a better understanding of their sustainability. renewable energy. volume 85, january 2016, pages 1328-1333. 